\section{ANEURISM OF THE INNOMINATA.}

Ir will be seen by the following letter, that the veteran Scarpa, who was reported dead, is not only still alive, but taking an undiminished interest in lis favourite science. He thus writes of Mr. Wardrop's operation:

[From the Edinburgh Mredical and Surgical Journal.]

Ertract of a Letter from Professor Scarpa to Mr. Wishart of Edinburgh.-I feel much gratified by your congratulation with regard to the prolongation of my life, which some journalists had thought proper to cat short.

I have been for nearly two years acquainted with Mr. Wardrop's splendid and fortunate operation of the ligature of the carotid aneurism seated deep under the sternum, and I am much pleased to hear from you, that some other similar operations have been performed with equally good success. We must allow that this mode of operating is not applicable to all cases of aneurism, but only to that just mentioned, in which there is, opposite to the origin of the carotid, a large artery almost of the same size as the carotid. And it is a fact, that this mode of operating is not at all applicable to the case of inguinal aneurism, because the profinda femoral artery is of a calibre much less than the external femoral artery. At all events, this discovery of Mr. "Wrardrop is valuable for the advancement of the art; and I regret that it was omitted in my work, although I entertainsd the hope that the blank might be filled up in a new edition of it, which is now publish. ing in Paris.

In the course of a month a new work of mine will be published here, under the title De Anatome et Pathologia Ossium Commentarii, with six plates. In this work I propose to review what I have already stated at a former time, with regard to the true structure of bone, and to rectify and arrange in better order, the most certain and important facts with regard to the essence of the diseases of the bones, and the artificial manner employed by nature in the formation of callus for the reunion of fractured bones, in all which subjects there is a want of precision in the doctrine of surgery.

Along with the books I am to send to you, you will receive a small work, from which you will perceive that we are acquainted with the possibility of arresting the progress of the incipient medullary fungrus of children, by means of the extirpation of the eyeball, which has been hitherto a subject of controversy. You will also find a memoir on a rare and perhaps unique case of diaphragmatic hernia, on the right side of the diaphragm, provided with a hernial sac, a very rare circumstance,

Pavia, May 21, 1827.

\section{ANEURISH OF THE INNOMINATA.}

\section{To the Editor of $\mathrm{T}_{\mathrm{He}} \mathrm{L}_{\mathrm{AnCET}}$.}

Sin,-May I beg you to do me the favour of inserting, in your invaluable Journal, the further account of the case of aneurism of the innominata, wherein I tied the subclavian artery, in order that the public may become acquainted with its progress, which, I am happy to say, has proceeded to my most sanguine expectations.

I have the honour to be,

Sir, yours, \&c.

JAMES WARDROP.

Continuation of the Case, where the Subclavian Artery was tied for the cure of an Aneurism of the Arteria Innominata. By J AMES

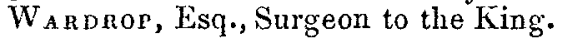

I HA ve already stated, (see LaNCET, ) that, immediately after the operation, this patient experienced a renarkable degree of relief, and that the peculiar sensations in her head were removed. Soon after she had been placed in bed, it was also evident that the pulsations of the aneurismal tumour had become much diminished in strength, and their impulse seemed to extend less high in the neck. She suffered no peculiar sensations in her arm; the pulse of the radial artery was imperceptible, and the heat of the limb did not seem to vary from the natural state. She had none of those sensa. tions of tingling and numbness, which are usually felt after the main artery of a limb has been tied.

The day after the operation, a slight thrill was perceptible in the radial artery, which has not since increased much in volume, and the heat of the aneurismal limb had sunk below its natural temperature. All the dis. tressing symptoms which formerly had harassed the patient, seemed to be rapidly disappearing. In this way she has gone on, sradually mending, without the occurrence of a single symptom requiring medical treatment, the wound having united completely by the first intention, except at the point where the ligature emerged. Her nights, which, before the operation, were passed in a state of restless inquietude, wele now spent in the most refreshing slumbers. 